Harvard Data Science Review • Issue 4.1, Winter 2022

\title{
The Role of FOMO in Digital Transformation
}

\section{Ben Dooley ${ }^{1}$}

${ }^{1}$ Infocepts, McLean, Virginia, United States of America

Published on: Jan 27, 2022

DOI: https://doi.org/10.1162/99608f92.2f71a69e

License: Creative Commons Attribution 4.0 International License (CC-BY 4.0). 
Editor's Note: Many businesses are experiencing FOMO (Fear Of Missing Out) on digital technologies. And yet, a rush to implement digital transformations is leading to projects failing to make the desired impact. As Ben Dooley writes, "Increasing the probability of success in digital transformation requires a new way of thinking."

Keywords: digital transformation, data analytics, digital innovation, digital technology

Digital transformation remains a ubiquitous term in 2021 and, with the post-COVID emergence of clear market winners in industries where dominant players have consolidated market presence by adopting digital technologies, a clear pattern has emerged: over $70 \%$ of digital technology and transformation projects fail to produce their intended business impacts (Morgan, 2019).

This phase of rapid transformation, to which many organizations are latecomers, is causing managers to operate from a position of FOMO, or fear of missing out, on the benefits that digital technologies have brought to their competitors. Managers are in a state of digital catch-up with digitally advanced competitors and, as a result, are prone to skip crucial steps required for successful projects.

To understand the driver behind this broad digital transformation push and the impacts of FOMO, let's look at a couple of examples. First, consider WeWork. When the company attempted (and subsequently retracted) its IPO in 2019, its market capitalization was \$47B (Pietsch, 2020). However, its IPO via Special Purpose Acquisition Company in 2021 yielded a valuation of only \$9.5B. WeWork initially marketed itself as a technology company transforming the commercial office space industry, when in function it is a real estate company with an app for booking and reserving office space and conference rooms. This is a company that marketed digital transformation but could have been more successful had it used its digital technologies to materially change the way it acquires and services customers.

Second, let's look at how the market values digital innovation. In January 2021, the price-earnings ratios in the retail industry ranged from 30 to 133, whereas the ratios in the software industry ranged from 92 to 193 (Damodaran, 2021), indicating that the market values software firms more than companies with traditional operating models like manufacturing. It is no wonder that every company wants to be a software company, and the easiest perceived way to become one is by leveraging vast amounts of data to implement digital transformation projects.

This valuation disparity is placing pressure on executives and driving FOMO on the higher multiples of other industries. FOMO comes from a psychological mindset of scarcity and, in a business context, often results in rushed, ad hoc products that don't provide the expected returns to customers and stakeholders. Additionally, given this rush toward digital transformation across industries, many managers find themselves in cutthroat competition with other industry leaders to acquire and retain scarce and ever more expensive talent. 
One director I spoke to, who wishes to remain anonymous, mentioned that his team was “drowning” under millions of dollars in data and analytics tools that, after 2 years, had yet to bring material value to their customers and likewise had yet to provide a return to his firm (personal communication, December 16, 2021). I also spoke to a lawyer at a \$2B firm, who also wishes to remain anonymous, attempting to build a customerfacing data product and dealing with delivery delays that were jeopardizing not only the revenue for his new product but also his firm's 10-year relationship with the client (personal communication, November 12, 2021). His challenges were not because the product did not meet a need, but rather because he did not have a productdriven process. Increasing the probability of success in digital transformation requires a new way of thinking. Successful projects follow a sound product management process steeped in an entrepreneurial spirit, thus creating a safe innovation space.

Approaching your digital transformation project in a holistic manner, be it focused on internal or external value creation, can drastically increase its chances of success. Devote time to the following considerations when mapping your organization’s digital transformation strategy:

1. Create an environment tolerant of fast failures to reduce the risk of unsuccessful outcomes for those involved in the experiments. Try to avoid holding innovators accountable for the same key performance indicators (KPIs) as established lines of business.

2. Test your product through sound market validation exercises and don’t be disappointed if your customers aren't receptive.

3. Start with your customer's 'Why?' Ask yourself and your customer why they would want a data-driven solution in the first place? What is the problem to be solved or the work to be done? Are your customers ready to operationalize your solution?

4. Constantly test your assumptions. Ideally, cross-functionally align your project teams to include marketing, sales, development, legal, operations, quality, and support in agile processes that incorporate customer feedback as a core tenant.

5. Ask yourself honestly if your company can adapt operations to meet the demands of the new digital offering.

The FOMO rush to play catch-up in digital transformation is leading to an increased number of projects that fail to make their desired impacts to businesses, especially as digital transformation projects expand to companies playing digital catch-up. Moreover, many companies frame these projects as IT projects rather than product development projects, and when the product is presented to customers, many times the company misses the mark. In order to increase your likelihood of success, plan for failure, plan for pivots, and be patient. After all, transformation is extremely difficult to manage and will ultimately serve as the operating platform for your business over the next several years. It's best to take your time and get it right. 


\section{Disclosure Statement}

Ben Dooley has no financial or non-financial disclosures to share for this article.

\section{References}

Damodaran, A. (2021). Price earnings ratio by sector (US). Damodaran Online.

https://pages.stern.nyu.edu/ adamodar/pc/archives/pedata20.xls

Morgan, B. (2019, September 30) Companies that failed at digital transformation and what we can learn from them. Forbes. https://www.forbes.com/sites/blakemorgan/2019/09/30/companies-that-failed-at-digital-

transformation-and-what-we-can-learn-from-them/?sh=63aba9a7603c

Pietsch, B. (2020, May 18). WeWork’s valuation has fallen from \$47B last year to \$2.9B. Business Insider. https://www.businessinsider.com/wework-valuation-falls-47-billion-to-less-than-3-billion-2020-5

(C)2022 Ben Dooley. This article is licensed under a Creative Commons Attribution (CC BY 4.0) International license, except where otherwise indicated with respect to particular material included in the article. 